Research Article

\title{
Experimental and Theoretical Investigations of a Displacement-Amplified Torsional Damper
}

\author{
Huimin Mao $\mathbb{D D}^{1}$ Xueyuan Yan $\mathbb{D},^{2}$ Xiangliang Ning $\mathbb{D}^{3},{ }^{3}$ and Shen Shi $\mathbb{D}^{2}$ \\ ${ }^{1}$ College of Ecological Environment and Urban Construction, Fujian University of Technology, Fuzhou, Fujian 350118, China \\ ${ }^{2}$ College of Civil Engineering, Fuzhou University, Fuzhou 350116, China \\ ${ }^{3}$ Zhuzhou Times New Material Technology Co., Ltd., Zhuzhou, Hunan 412007, China
}

Correspondence should be addressed to Xueyuan Yan; yxy820910@sina.com

Received 30 June 2021; Accepted 11 September 2021; Published 30 September 2021

Academic Editor: Rui Moreira

Copyright (C) 2021 Huimin Mao et al. This is an open access article distributed under the Creative Commons Attribution License, which permits unrestricted use, distribution, and reproduction in any medium, provided the original work is properly cited.

In this work, a displacement-amplified torsional damper (DATD) is proposed for improving the seismic capacity of the beamcolumn joints of a frame structure. The proposed DATD uses common steel, lead, and high-damping rubber. This damper exhibits good energy dissipation under small earthquakes. Under strong earthquakes and large displacements, the strengthening of the high-damping rubber can improve the overall stiffness of the damper and increase the energy dissipation. In order to investigate the performance of the proposed DATD, theoretical analyses, simulations, and cyclic loading tests were performed, and their results were compared, showing an overall good agreement.

\section{Introduction}

Energy dissipation can be achieved via a structural vibrationcontrol method that dissipates seismic energy by installing energy-dissipating members or dampers on some parts of the structure. Dampers can be used efficiently to dissipate energy. Furthermore, being independent from the structure, dampers can be easily installed and disassembled. Owing to these advantages and their low costs, dampers are used widely. The most commonly used dampers are metallic yield dampers, friction dampers, shape memory alloy (SMA) dampers, viscoelastic dampers, etc. Compared with dampers with a single energy dissipation mechanism, composite dampers with two or more energy dissipation mechanisms have more prominent advantages. Common composite dampers include steel-tube dampers, combined steel-lead dampers, lead viscoelastic dampers, steel viscoelastic dampers, and mixed-steel yielding-friction energy dissipators.

Various new types of composite dampers have been proposed. Xin and Cheng [1] presented an I-section combined steel-lead damper (CSLD). Performance tests and finite element simulations showed that this CSLD was an excellent damper with a good hysteretic performance and a stable energy dissipation capacity. Li et al. [2] proposed a recentering SMA-lead damper (RSLD). The seismic response of a six-story steel-frame structure, where different dampers had been installed, was investigated, and the results showed that these RSLDs have an outstanding recentering capacity. Some researchers have proposed combining magnetorheological (MR) dampers with other types of dampers. Zhang et al. [3] proposed a combined magnetorheological (CMR) damper composed of a MR damper and a leadsqueeze damper. The nonlinear hysteresis behavior, energy dissipation capability, and fatigue characteristics of this CMR damper were studied. Zhong et al. [4] implemented a new viscoelastic damper using the magnetorheological effect to compensate for the thermal softening effect of viscoelastic materials. The experimental results showed that this new type of viscoelastic damper is not affected by ambient temperature, thus being able to retain the best energy consumption performance at various temperatures.

The combination of metal and viscoelastic dampers can effectively reduce the displacement and the acceleration response of a structure. Sanati et al. [5] proposed a rotatingfriction viscoelastic damper. Silwal et al. $[6,7]$ designed a 
superelastic viscous damper composed of a SMA damper and a viscoelastic damper. Fang et al. [8] presented two types of hybrid brace incorporating shape memory alloy elements and integrated viscoelastic dampers. Banisheikholeslami et al. [9] studied a viscoplastic damper (VPD) combining the highdamping rubber viscoelastic energy dissipation and the elastoplastic steel bolt energy dissipation. Yamamoto and Sone [10] investigated a damper system consisting of a serial connection between a metallic yielding damper and a viscoelastic damper with a displacement limit mechanism. Vargas and Bruneau [11] studied the seismic performance of a SDOF system with metallic and viscous dampers installed in parallel. Soltanabadi et al. [12] proposed a rubber steel-core damper (RSCD) exhibiting a regular and stable hysteresis performance. Furthermore, theoretical and experimental studies on the mechanical properties and vibration-control performance of lead rubber dampers were conducted, respectively, by Kim et al. [13] and Zeynali et al. [14]. In these works, the damping effect of these newly proposed composite dampers was investigated through numerical simulations and experiments.

Combining dampers with different energy dissipation mechanisms can result in dampers working in stages to improve the seismic performance of a structure under multilevel earthquakes. Yan et al. [15] proposed a lead-extrusion and friction composite damper (LEFCD) which can dissipate energy in stages. It was reported that this LEFCD has different mechanical models which can meet the various damping needs of buildings. Lee et al. [16] developed a steel seam-friction damper. The results of the experiments and finite element analyses showed that this damper has a good energy dissipation effect. Lee et al. [17] proposed a new hybrid damper which combines a friction damper and a steel-strip damper to improve the seismic performance of structures under multilevel ground motion. Roh et al. [18] designed a multiaction hybrid damper and verified its control performance for building structures under wind or earthquake conditions. Ibrahim et al. [19] proposed a new type of VPD that can amplify strain. Under small earthquakes, the VPD dissipates energy only by amplifying the axial strain of the viscoelastic material, whereas, under medium and large earthquakes, it dissipates energy by the viscoelastic material and the yield metal at the same time.

Composite dampers have their own advantages and disadvantages, but most composite dampers cannot be directly installed on the beam-column joints that are prone to damage in earthquakes. This possibility would reduce the relative displacement of the beam-column angle and improve the energy dissipation effect at small displacements. Since relatively few types of lead viscoelastic composite damper exist, they should be developed and investigated further.

In this work, a displacement-amplified torsional damper (DATD) capable of amplifying the displacement is proposed. This composite damper uses common steel, lead, and high-damping rubber, with a simple and unique construction, and can be directly installed on the beam-column joints. The proposed DATD dissipates energy by shearing lead and rubber. The energy dissipation effect of the damper is controllable by adjusting the construction parameters of the lead core and the rubber layer. The DATD can amplify the small displacements between the beams and the columns under small earthquakes. Additionally, it can convert small displacements into large displacements between the rubber, the lead core, and the steel plate through the principle of concentric circles. The content of the present article is arranged as follows. The DATD construction is introduced first. The theoretical derivation to establish a mechanical model suitable for the proposed DATD is then discussed. Next, the results of a cyclic loading test are presented, alongside with those from numerical analyses and experiments. Finally, the theoretical, numerical, and experimental results are compared.

\section{Introduction to DATD}

As shown in Figure 1, the DATD is installed on the beamcolumn joints. It consists of a high-damping rubber layer, an upper gear cylinder, an upper round steel plate, a middle round steel plate, a lower round steel plate, a lower gear cylinder, a lead core, and a transmission steel arm. The high-damping rubber layer is vulcanized into one body with the middle round steel plate and the upper and lower round steel plates. The main body of DATD is connected to the column through a T-shaped steel connecting plate. One end of the transmission steel arm is fixed to the beam via bolts, and the other end is connected to the gear through the transmission teeth of the transmission arm. Overall, the damper is a symmetrical structure, with four cylindrical lead cores penetrating through the steel plates and the rubber layer. The damper dissipates energy by shearing the lead, which has displacement-dependent characteristics. If the high-damping rubber layer was to be replaced with a viscoelastic material, it would also have velocity-dependent characteristics. The diameter of the gear cylinder is smaller than that of the round steel plate. By adjusting their relative sizes, the displacement-amplification effect can be controlled. There is a cylindrical protrusion under the upper and lower round steel plates, which is embedded into the groove of the middle round steel plate. This is equivalent to a torsion fulcrum twist of the upper and lower round steel plates around the torsion fulcrum. When the beam-column is angularly displaced, it induces rotation in the connected transmission steel arm. The transmission steel arm then drives the upper and lower round steel plates to twist and shear, while the high-damping rubber and lead core dissipate energy. The main components required to achieve the desired energy dissipation are the high-damping rubber and the lead core. The damper is replaceable. After it is damaged, the damper can be replaced by removing and reinstalling the bolts connecting the damper to the structural beam and column. The damper has good durability, and no special maintenance is required except for the antirust of the steel.

The damping force is affected by the diameter of the lead core, the distance between the lead core and the central axis, the diameter of the rubber layer, the thickness of the rubber layer, and the rubber shear modulus of the DATD. All these components need to be designed according to the actual situation. 


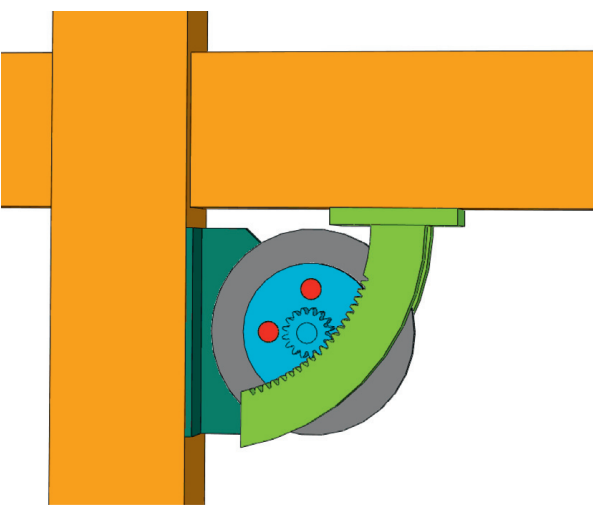

(a)

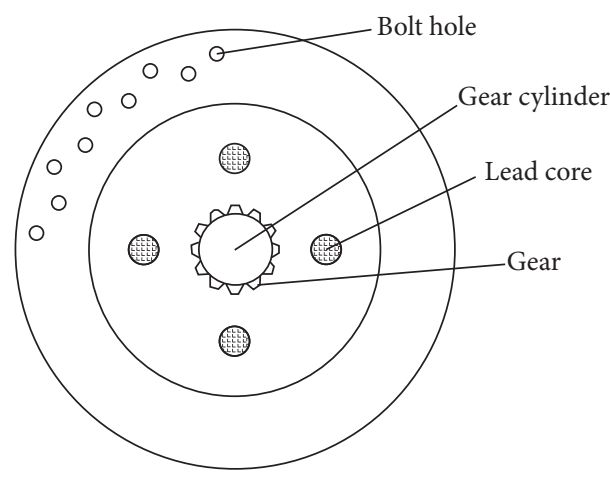

(c)

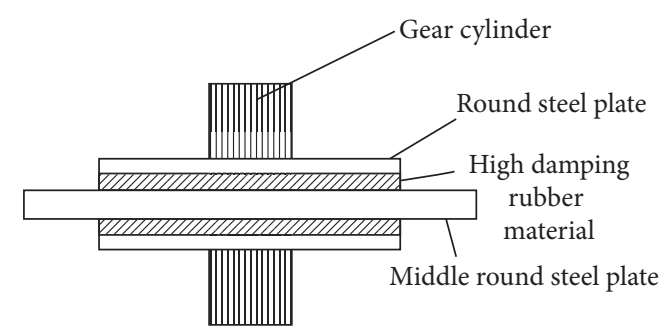

(b)

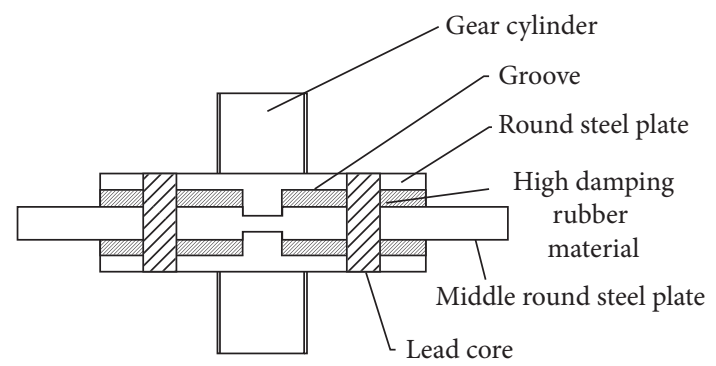

(d)

Figure 1: Drawings of the proposed DATD: (a) 3D view of the installation. (b) Elevation drawing. (c) Plan drawing. (d) Section drawing.

\section{Mechanical Model of the DATD}

3.1. Mechanical Model of the Lead Core. The mechanical model of the lead core can be described through a uniformly deformed ideal elastic-plastic model [20]. Figure 2 illustrates the planar sketch for deriving the mechanical model of the lead core in the DATD.

The mechanical model of the lead core can be described as

$$
\left\{\begin{array}{c}
\tau=G_{\mathrm{L}} \gamma \\
\tau=\tau_{\mathrm{y}}
\end{array}\right\} \begin{aligned}
& 0 \leq \gamma \leq \gamma_{\mathrm{y}} \\
& \gamma_{\mathrm{y}} \leq \gamma
\end{aligned}
$$

where $G_{L}$ is the shear modulus of the lead core, and $\gamma_{y}$ is the yield shear strain of the lead core.

When analyzing the deformation of the lead core, considering that the latter will undergo not only shear deformation but also torsion deformation, an influence coefficient has to be introduced into the geometric relationship of the lead core. This can be expressed as $\gamma=\tan \gamma=\Delta / a H$, where $a$ is the influence coefficient. The shear torsion coefficient is defined as $\rho=a^{2}$. According to the principle of energy conservation, namely, $W=U$, the formula for the lead core damping force of the DATD can be derived:

$$
\begin{array}{ll}
F=\frac{G_{\mathrm{L}} A_{\mathrm{L}}}{\rho H} \Delta, & 0 \leq \Delta \leq \Delta_{\mathrm{y}}, \\
F=F_{\mathrm{y}}=\tau_{\mathrm{y}} A_{\mathrm{L}}, & \Delta_{\mathrm{y}} \leq \Delta \leq \Delta_{\mathrm{m}} .
\end{array}
$$

The shear stiffness of a single lead core in the DATD is

$$
K_{\mathrm{L}}=\frac{G_{\mathrm{L}} A_{\mathrm{L}}}{\rho H} .
$$

From the yield shear force $F_{\mathrm{y}}=\tau_{\mathrm{y}} A_{\mathrm{L}}$, the yield displacement of the lead core can be derived:

$$
\Delta_{\mathrm{y}}=\frac{\tau_{\mathrm{y}}}{G_{\mathrm{L}}} \rho H=\frac{\tau_{\mathrm{y}}}{G_{\mathrm{L}}} h, \quad h=0.5\left(H-4 H_{\mathrm{S}}\right),
$$

where $F$ is the shear force of the lead; $K_{\mathrm{L}}$ is the shear stiffness of the lead; $G_{L}$ is the shear modulus of the lead; $\Delta$ is the shear displacement; $A_{\mathrm{L}}$ is the shearing area of the lead; $h$ is the calculated height of the yield displacement of the damper; $H$ is the total height of the lead core; $H_{\mathrm{S}}$ is the thickness of the upper and lower steel plates; $2 H_{\mathrm{S}}$ is the thickness of the middle steel plate; $\tau_{\mathrm{y}}$ is the yield stress of the lead core, here assumed to be $10.5 \mathrm{MPa}$.

3.2. Mechanical Model of Rubber. The high-damping rubber used in the DATD consists of a highly elastic polymer material with reversible deformation, and its load is positively correlated with the deformation. The mechanical model shows that the rubber has a strengthening effect.

Figure 3 displays the force diagram of the shear deformation of the DATD. The lateral deformation of the beamcolumn joints forces the round steel plate of the damper to shear the rubber layer. The vulcanized bonding part of the round steel plate and the rubber layer in Figure 3 can be 


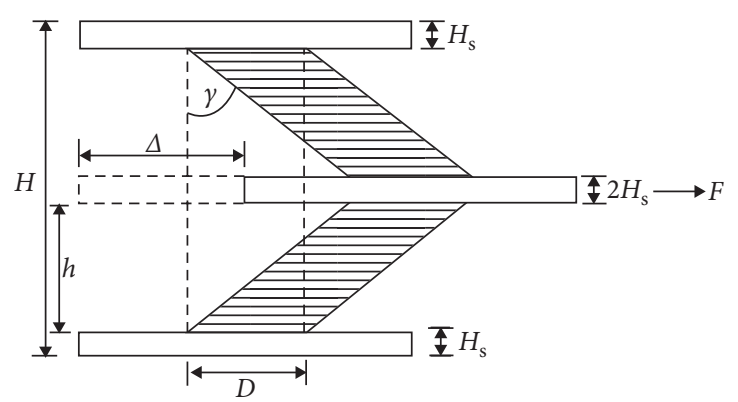

Figure 2: Structure and shear deformation of the lead core. $F$ : the shear force of the lead core, $H$ : the total height of the lead core, $H_{s}$ : the thickness of the upper and lower steel plates, $2 \mathrm{H}_{\mathrm{s}}$ : the thickness of the middle steel plate, $h$ : the calculated height of the yield displacement of the lead core, $\gamma$ : the shear strain, $\Delta$ : the shear displacement, $D$ : the diameter of the lead core.

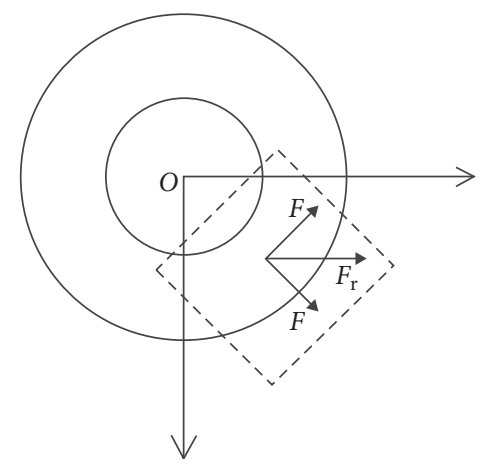

FIGURE 3: Force diagram of the shear deformation of the rubber layer in the DATD. F: shear force along length or width of the rectangular shear plate, $F_{\mathrm{r}}$ : resultant shearing force of the quarterring steel plate.

regarded as a ring. For the analysis, a quarter circle can be used, which is approximately equal to a rectangular region with the same area (marked via a dotted line in Figure 3 ). The shear force in both directions of the equivalent area is calculated as follows: $F=\beta K_{\mathrm{v}} \Delta$, where $\beta$ is the hardness correction coefficient of the rubber, $\Delta$ is the shear displacement, and $K_{\mathrm{v}}$ is the unidirectional shear stiffness of the rubber layer. Thus, the shear force in the horizontal direction is $F_{\mathrm{r}}=\sqrt{2} \beta K_{\mathrm{v}} \Delta, 0, \Delta \leq \Delta_{\mathrm{m}}$. The direction of $F_{\mathrm{r}}$ is shown in Figure 3 . Therefore, the shearing force of a quarter of the rubber deformation driven by the middle round steel plate in the DATD can be calculated according to the following equation.

$$
F_{\mathrm{r}}=\sqrt{2} \beta K_{\mathrm{v}} \Delta=1.414 \beta K_{\mathrm{v}} \Delta, \quad 0 \leq \Delta \leq \Delta_{\mathrm{m}} .
$$

The shear stiffness of the rubber layer is affected by many factors and is calculated according to the pure shear condition. Combining the pure shear condition with (5), the shear stiffness of the rubber layer can be written according to

$$
K_{\mathrm{r}}=4 \sqrt{2} K_{\mathrm{v}}=4 \sqrt{2} \frac{G_{\mathrm{r}} A_{\mathrm{r}}}{h_{\mathrm{r}}}=5.656 \frac{G_{\mathrm{r}} A_{\mathrm{r}}}{h_{\mathrm{r}}},
$$

where $F$ is the shear force of the rubber, $K_{\mathrm{v}}$ is the unidirectional shear stiffness of the rubber layer, $K_{\mathrm{r}}$ is the shear stiffness of the rubber layer, $\Delta$ is the shear displacement, $\beta$ is the correction coefficient of the hardness of the rubber, $A_{\mathrm{r}}$ is the effective shearing area of the rubber layer, $G_{\mathrm{r}}$ is the shear modulus of the rubber, and $h_{\mathrm{r}}$ is the total thickness of the rubber layer.

3.3. Restoring Force Model of the DATD. Under the action of cyclic loading, the lead core in the DATD undergoes an ideal elastic-plastic deformation, whereas the rubber still maintains the superelastic deformation. Figure 4 shows the restoring force model within a limit of $1 / 50$ of the elastoplastic displacement angle between the different stories of a structure.

The first part of the figure represents the ideal elasticplastic restoring force model corresponding to the lead core, whereas the second part represents the nonlinear restoring force model corresponding to the rubber. The combination of the two is approximated by a double-polyline restoring force model, characterized by a parallelogram [21], as shown in the third part of the figure. Therefore, within a limit of $1 / 50$ of the elastoplastic displacement angle between the stories of a structure, the mechanical model of DATD can be represented by a bilinear model. Figure 5 shows the bilinear restoring force model of the DATD, which defines the parameters of the restoring force model.

Lead Rubber DATD.

The initial stiffness is

$$
K_{1}=\frac{F_{\mathrm{y}}}{u_{\mathrm{y}}} .
$$

The stiffness after yield is

$$
K_{2}=\frac{F_{\mathrm{m}}-F_{\mathrm{y}}}{u_{\mathrm{m}}-u_{\mathrm{y}}} .
$$

The equivalent stiffness is

$$
\begin{aligned}
K_{\mathrm{e}} & =K_{1}\left(\frac{1-\alpha}{\mu}+\alpha\right), \\
\alpha & =\frac{K_{2}}{K_{1}} \\
\mu & =\frac{u_{\mathrm{m}}}{u_{\mathrm{y}}}
\end{aligned}
$$




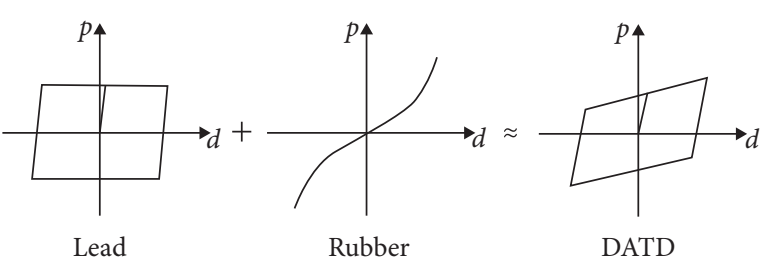

FIgURE 4: Restoring force model of the DATD.

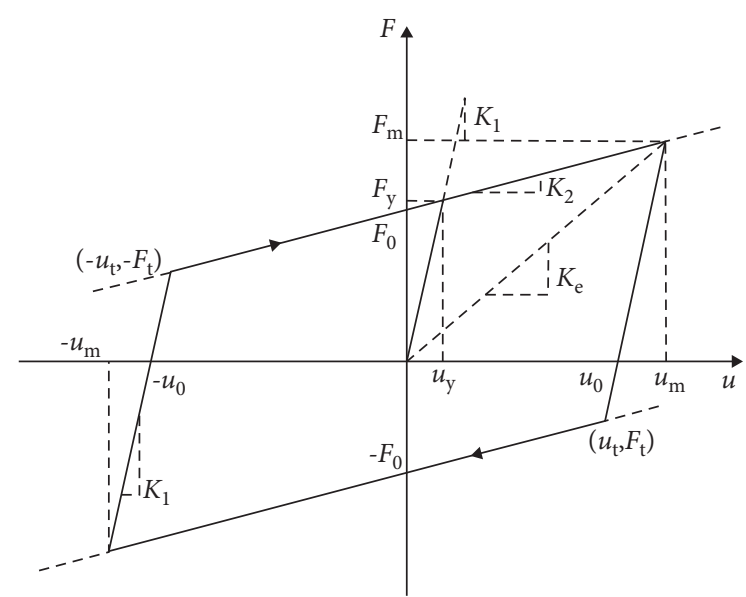

FIGURE 5: Bilinear mechanical model. $K_{1}$ : initial stiffness, $K_{2}$ : stiffness after yield, $K_{\mathrm{e}}$ : equivalent stiffness, $\left(u_{\mathrm{y}}, F_{\mathrm{y}}\right)$ ) (yield displacement, yield shear force), $\left(u_{\mathrm{m}}, F_{\mathrm{m}}\right)$ : (maximum displacement, shear force corresponding to the maximum displacement), $F_{0}$ : feature strength of the damper (shear force provided by the damper when the displacement is zero), $u_{0}$ : feature displacement of the damper (displacement of the damper when the shear force is zero), $\left(u_{t}, F_{t}\right)$ : displacement of the yield point under reverse loading and corresponding shear force.

where $\alpha$ is the reduction coefficient of the second stiffness, and $\mu$ is the ductility coefficient.

Based on the above formula, it can be inferred that, during the stage of elastic deformation of the DATD, the initial stiffness $K_{1}$ of the damper is considered as the sum of the shear stiffness of the lead core and the shear stiffness of the rubber layer. The hardness correction factor $\beta$ is introduced to adjust the shear stiffness of the rubber layer, represented by $\beta K_{\mathrm{r}}$, where $K_{\mathrm{r}}$ is given by equation (6). The initial stiffness of the DATD then becomes $K_{1}=n_{\mathrm{L}} K_{\mathrm{L}}+\beta K_{\mathrm{r}}$. Additionally, its yield displacement can be approximated to the yield displacement of the lead core, that is, $u_{\mathrm{y}}=\tau_{\mathrm{y}} / G_{\mathrm{L}} h$. The stiffness after yielding $K_{2}$ depends on the shear stiffness of the rubber layer [22], that is, $K_{2}=\beta K_{\mathrm{r}}$. In summary, the equations for the restoring force model of the DATD, according to the different stages, are

Elastic stage:

$$
F_{\mathrm{z}}=K_{1} u=\left(n_{\mathrm{L}} K_{\mathrm{L}}+\beta K_{\mathrm{r}}\right) u, \quad 0 \leq u \leq u_{\mathrm{y}} .
$$

Plastic yield stage:

$$
F_{\mathrm{z}}=K_{2} u+F_{0}, \quad u_{\mathrm{y}} \leq u \leq u_{\mathrm{m}} .
$$

Elastic unloading stage:

$$
F_{\mathrm{z}}=K_{1} u-F_{1}=\left(n_{\mathrm{L}} K_{\mathrm{L}}+\beta K_{\mathrm{r}}\right) u-F_{1}, \quad u_{\mathrm{t}} \leq u \leq u_{\mathrm{m}} .
$$

Reverse-loading plastic yield stage:

$$
F_{\mathrm{z}}=K_{2} u-F_{0}, \quad-u_{\mathrm{m}} \leq u \leq u_{\mathrm{t}} .
$$

Elastic recovery stage:

$F_{\mathrm{z}}=K_{1} u+F_{1}=\left(n_{\mathrm{L}} K_{\mathrm{L}}+\beta K_{\mathrm{r}}\right) u+F_{1}, \quad-u_{\mathrm{m}} \leq u \leq-u_{\mathrm{t}}$.

Plastic yield recovery stage:

$$
F_{\mathrm{z}}=K_{2} u+F_{0}, \quad-u_{\mathrm{t}} \leq u \leq u_{\mathrm{y}},
$$

where $u_{\mathrm{y}}=\tau_{\mathrm{y}} / G_{\mathrm{L}} h$. From equations (11) and (12) the following equations can be derived:

$$
F_{0}=K_{1}-K_{2} u_{\mathrm{y}}=n_{\mathrm{L}} K_{\mathrm{L}} u_{\mathrm{y}} .
$$

From equations (12) and (13) the following equations can be derived:

$$
F_{1}=\left(K_{1}-K_{2}\right) u_{\mathrm{m}}-F_{0}=n_{\mathrm{L}} K_{\mathrm{L}}\left(u_{\mathrm{m}}-u_{\mathrm{y}}\right) .
$$

From equations (13) and (14) the following equations can be derived:

$$
u_{\mathrm{t}}=\frac{F_{1}-F_{0}}{n_{\mathrm{L}} K_{\mathrm{L}}}=u_{\mathrm{m}}-2 u_{\mathrm{y}}
$$

Furthermore, the following equations can be derived:

$$
F_{\mathrm{t}}=K_{1} u_{\mathrm{t}}-F_{1} \text {. }
$$

In these equations, force.

$\left(u, F_{z}\right)$ is the displacement and corresponding shear

$K_{1}$ is the initial stiffness; $K_{2}$ is the stiffness after yield; $K_{\mathrm{L}}$ is the shear stiffness of the single lead core, referring to equation (3); $K_{\mathrm{r}}$ is the shear stiffness of the rubber layer, referring to equation (6); $n_{\mathrm{L}}$ is the number of lead cores; $F_{0}$ is the feature strength of the damper (the value of the intersection between the hysteresis curve and the load axis); $F_{\mathrm{y}}$ is the yield force; $F_{1}$ is the value of the intersection between the hysteresis curve in the reverse-loading elastic stage and the load axis; $u$ is the shear deformation; $u_{\mathrm{m}}$ is the maximum displacement; $u_{0}$ is the feature displacement of the damper (the intersection value between the hysteresis curve and the load axis); $\left(u_{\mathrm{t}}, F_{\mathrm{t}}\right)$ is the displacement of the yield point under reverse loading and corresponding shear force; $u_{\mathrm{y}}$ is the yield displacement, referring to equation (4); $\beta$ is the hardness correction coefficient of the rubber (its value [23] can be found in Table 1 and obtained by linear interpolation).

The displacement and force used above can be converted into the relative torsion angle and moment of the damper, and the calculation formula is as follows: 
TABLE 1: Hardness of rubber.

\begin{tabular}{lcc}
\hline Hardness of rubber $( \pm 2)$ & $G(\mathrm{MPa})$ & $\beta$ \\
\hline 30 & 0.30 & 0.93 \\
35 & 0.39 & 0.89 \\
40 & 0.46 & 0.85 \\
45 & 0.54 & 0.80 \\
50 & 0.64 & 0.78 \\
55 & 0.83 & 0.73 \\
60 & 1.08 & 0.64 \\
\hline
\end{tabular}

$$
\begin{gathered}
\theta=\frac{u}{l}, \\
M=F l,
\end{gathered}
$$

where $l$ is the distance between the lead core and the central axis, and $M$ is the moment of the damper.

\section{Performance Test of the DATD}

4.1. Overview of the Physical Model. The parameters of the DATD specimen are shown in Table 2. The high-damping rubber used in the specimen was provided by Hunan Zhuzhou Times New Material Technology Co., Ltd. The steel was Q345, and the lead core was made of common lead. The production process was as follows: (1) mold fabrication; (2) material preparation; (3) parts processing; (4) high-temperature and high-pressure vulcanization; (5) lead core setting and base limit plate welding; (6) marking the outer circumferential surface of the steel plate and the rubber layer for easy observation. The physical model of the specimen is shown in Figure 6.

4.2. Test Program. A base was processed in advance to fix the damper, and a spur gear drive rod was used to connect it with the actuator of the testing machine. Cyclic loading tests of the DATD were performed. The MTS electrohydraulic servo testing machine was used along the vertical direction during the tests. The data, such as the load and the loading displacement, were collected in real time. Moreover, the YHD-100 displacement sensor was installed onto the middle and the upper round steel plates, and the actual displacement and the displacement difference between the middle and the upper round steel plates were checked by comparing them, as shown in Figure 7 . The five cases in the experiment are shown in Table 3.

4.3. Test Processes and Results. In order to clearly observe the test results, the outer circumferential surface of the round steel plate and the rubber layer were painted in white with spray paint, and the word "HONG" was written with a black marker on the seam between the round steel plate and the rubber layer. The displacement of the round steel plate and the rubber layer, as well as the damage of the rubber layer, were observed through the deformation of the text mark.
4.3.1. Case $1(0.02 \mathrm{~Hz})$. The initial state of the damper specimen is shown in Figure 8(a). Firstly, the performance test for Case 1 was carried out. Under a loading displacement of 1 to $2.5 \mathrm{~mm}$, the relative rotation angle between the round steel plate and the rubber layer was found to be small, and the test results were not clear. Under a loading displacement of $5 \mathrm{~mm}$, the text mark on the round steel plate and the rubber layer began to tilt slightly, as shown in Figure 8(b). Upon gradually increasing the loading displacement, the tilt of the text mark became larger, and a rubbing sound could be occasionally heard from inside the damper. When the loading amplitude was set to $15 \mathrm{~mm}$, the text mark on the round steel plate and the rubber layer was obviously deformed. The original connecting straight lines at the seam were found to be misaligned, and the rubber layer shrank inwards. The straight lines on the rubber layer were twisted into oblique lines. The adhesive spilled rubber on the seam between the round steel plate and the rubber layer peeled off, and microcracks became visible in several locations.

In this case, the energy dissipation and deformation of the damper were stable, and the damping force was relatively large. There was no sign of damage to the damper during this process.

4.3.2. Case $2(0.05 \mathrm{~Hz})$. Case 2 was similar to Case 1 . As the displacement loading amplitude was progressively increased, the rubber layer gradually exhibited an observable shear deformation, and the text mark also began to tilt. When the loading amplitude reached the maximum value of $15 \mathrm{~mm}$ in the positive direction, the text mark was greatly deformed. Also in this case, the damper showed no signs of damage at the end of the experiment.

4.3.3. Case $3(0.1 \mathrm{~Hz})$. During the loading process, the test results of Case 3 were almost identical to those of Case 1 and Case 2. However, the loading process for Case 3 proceeded faster and took less time. In other words, it could be clearly observed that the text mark on the rubber layer had a tendency to move back and forth. When the displacement amplitude was set to $15 \mathrm{~mm}$, a slight friction sound could be heard near the lead core, and the rubber layer also made a slight noise, which was caused by the shock and vibration between the parts due to the faster loading rate. After the test, the damper showed again no signs of damage.

4.3.4. Case 4 (Fatigue Test). During this test, the text mark was found to tilt back and forth, whereas the rubber layer twisted back and forth and continued to twist and pinch. Furthermore, the gear-bite part of the straight teeth and the middle round steel plate slipped, and a clear gap appeared during repeated motion. Meanwhile, a greater friction was generated when the straight teeth was pressed down, since the installed limit plate was not parallel to the straight teeth, as shown in Figure 9. At the end of the fatigue test, no delamination was observed between the round steel plate and the rubber layer. The appearance and construction of the 
TABle 2: Parameters of the DATD specimen.

\begin{tabular}{lcccccccc}
\hline $\begin{array}{l}\text { Radius of } \\
\text { gear } \\
\text { cylinder, } r_{1} \\
(\mathrm{~mm})\end{array}$ & $\begin{array}{c}\text { Radius of } \\
\text { rubber } \\
\text { layer, } r_{2} \\
(\mathrm{~mm})\end{array}$ & $\begin{array}{c}\text { Radius of } \\
\text { middle steel } \\
\text { plate, } R \\
(\mathrm{~mm})\end{array}$ & $\begin{array}{c}\text { Thickness of } \\
\text { upper and lower } \\
\text { steel plate, } h_{\mathrm{s} 1} \\
(\mathrm{~mm})\end{array}$ & $\begin{array}{c}\text { Thickness of } \\
\text { middle steel } \\
\text { plate, } h_{\mathrm{s} 2}(\mathrm{~mm})\end{array}$ & $\begin{array}{c}\text { Thickness of } \\
\text { rubber layer, } \\
h_{\mathrm{r}}(\mathrm{mm})\end{array}$ & $\begin{array}{c}\text { Distance } \\
\text { between lead } \\
\text { core and central } \\
\text { axis, } a_{1}(\mathrm{~mm})\end{array}$ & $\begin{array}{c}\text { Diameter of } \\
\text { lead core, } \Phi \\
(\mathrm{mm})\end{array}$ & $\begin{array}{c}\text { Shear } \\
\text { modulus of } \\
\text { rubber, } G_{\mathrm{r}} \\
(\mathrm{MPa})\end{array}$ \\
\hline 50 & 200 & 300 & 20 & 40 & 20 & 125 & 60 \\
\hline
\end{tabular}

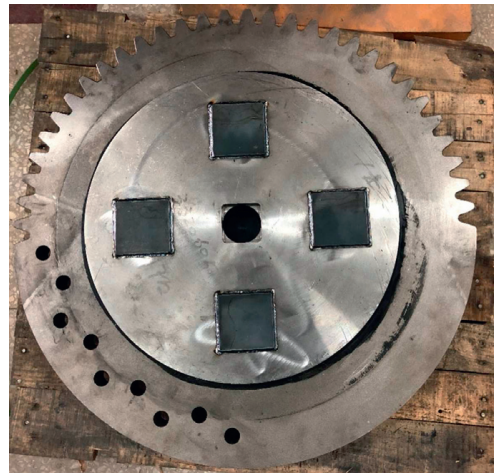

(a)

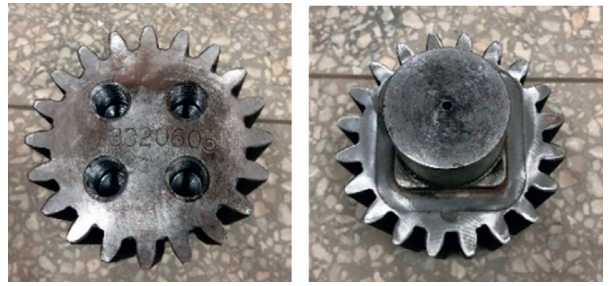

(b)

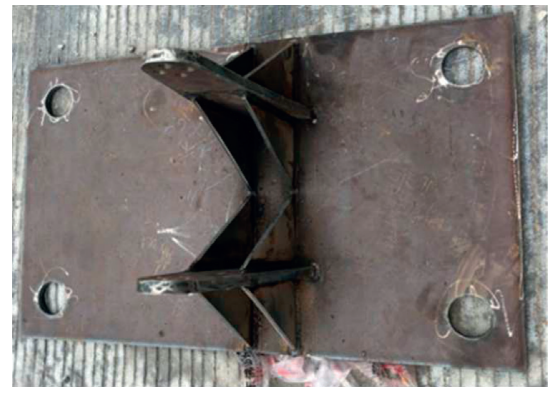

(c)

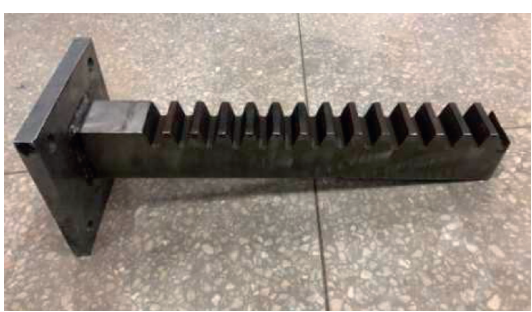

(d)

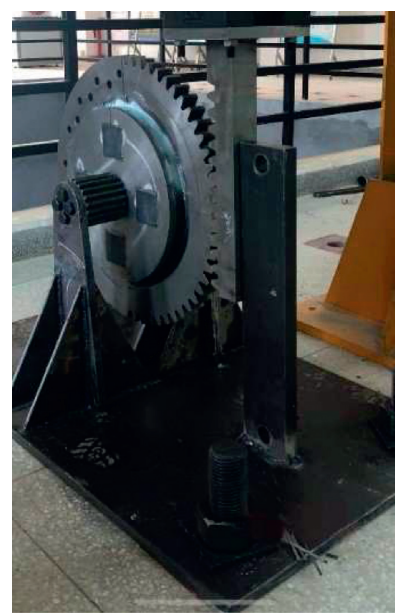

(e)

Figure 6: Physical model of the DATD. (a) Damper body (before installation). (b) Gear cylinder. (c) Base. (d) Straight teeth. (e) DATD on the base.

damper were found to be still intact, and there were no clear signs of low-cycle fatigue.

4.3.5. Case 5 (Large Deformation Test). Under sinusoidal excitation with a loading frequency of $0.1 \mathrm{~Hz}$, the specimen was gradually loaded with a displacement amplitude increasing from 1 to $30 \mathrm{~mm}$. Before reaching the $15 \mathrm{~mm}$ displacement amplitude, the test results were found to be similar to those of Case 2. With a displacement amplitude of $20 \mathrm{~mm}$, the inclination of the text mark increased further, and the rubber layer was observed to twist and pinch further, as shown in Figure 10(a). When loading with a displacement amplitude of $30 \mathrm{~mm}$, a rubbing "hissing" sound could be clearly heard from the rubber. The text mark reached the maximum inclination, and the rubber layer shrank significantly, as shown in Figure 10(b). The straight teeth and the middle round steel plate exhibited a larger contact gap, and the limit plate was slightly inclined outwards. $2 \mathrm{~mm}$ wide gaps could be observed in the seam between the rubber layer and the round steel plate (as shown in Figure 10(c)); however, they did not expand inwards. This fatigue damage was caused by the repeated pulling action in each previous case. At completion of the large deformation test, the text mark was still tilted, as shown in Figure 10(d), indicating that the deformation of the rubber and lead core is irreversible under such cases.

For the whole duration of the large deformation test, there was no apparent damage caused to the damper, and its working performance was found to be stable. 


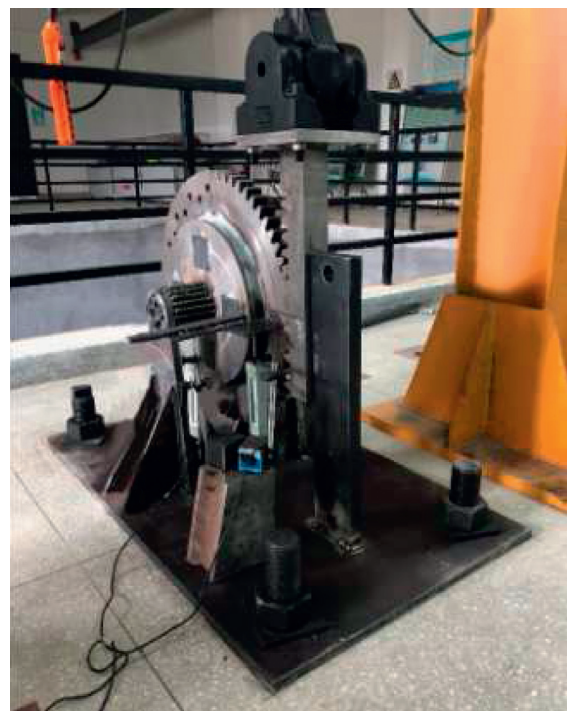

Figure 7: Measurement system.

TABle 3: Five cases in the experiment.

\begin{tabular}{lccc}
\hline Case & Loading displacements $(\mathrm{mm})$ & Loading frequency $(\mathrm{Hz})$ & Cycles \\
\hline 1 & $1,2.5,5,10,15$ & 0.02 & 3 \\
2 & $1,2.5,5,10,15$ & 0.05 & 3 \\
3 & $1,2.5,5,10,15$ & 0.1 & 3 \\
4 (fatigue test) & 5,15 & 0.1 & 30 \\
5 (large deformation test) & $1,2.5,5,10,15,20,25,30$ & 3 \\
\hline
\end{tabular}

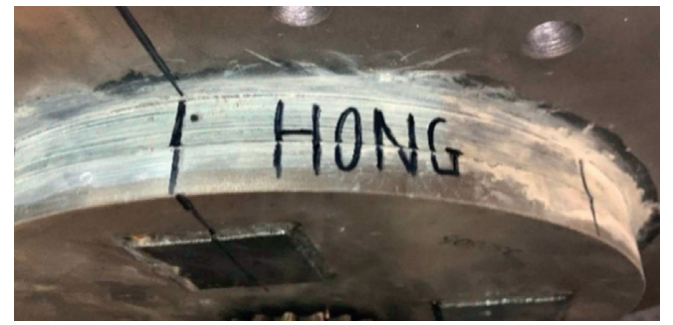

(a)

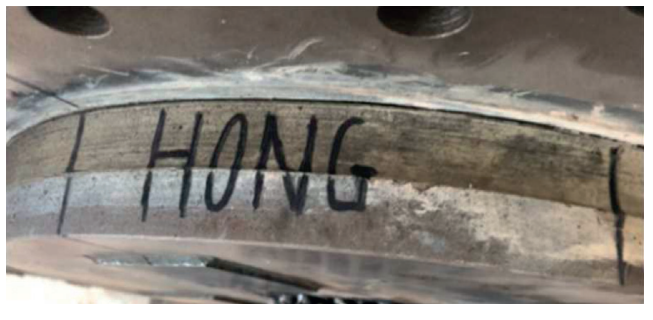

(b)

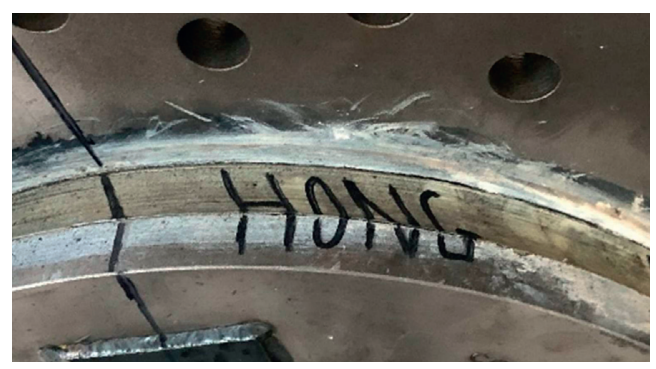

(c)

Figure 8: Loading process for Case 1. (a) Initial state. (b) Under $5 \mathrm{~mm}$ displacement. (c) Under $15 \mathrm{~mm}$ displacement.

4.4. Results and Analyses. At completion of the performance test of the DATD, the bending moment-angle hysteresis curves of the damper under various cases were obtained, as shown in Figure 11.
It can be seen from the hysteresis loops that the bending moment-angle curve appears as a straight line after yielding, and the damping force increases with the increase of the loading displacement. During the unloading stage, a diagonal 


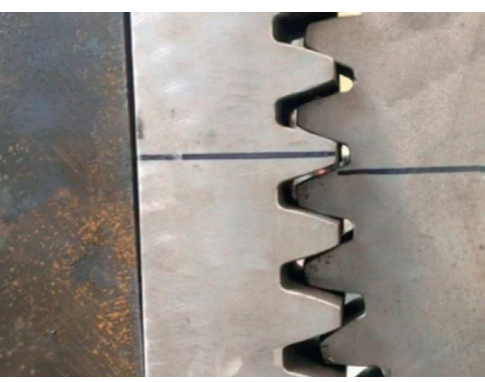

(a)

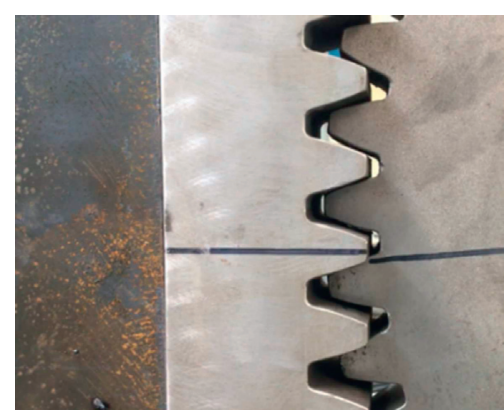

(b)

Figure 9: Loading process for Case 4. (a) Partial view of the straight teeth contact (while pulling up). (b) Partial view of the straight teeth contact (while pressing down).

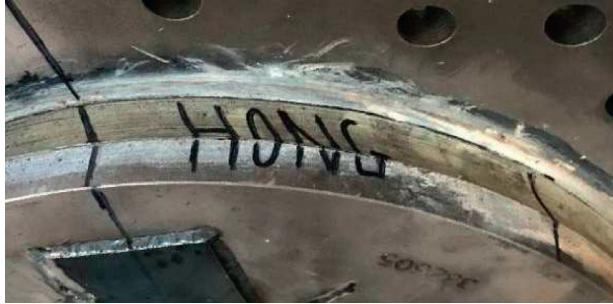

(a)

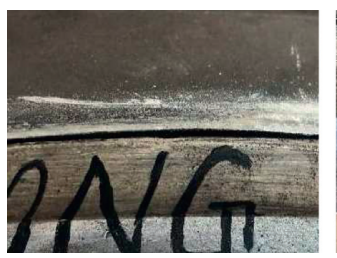

(c)

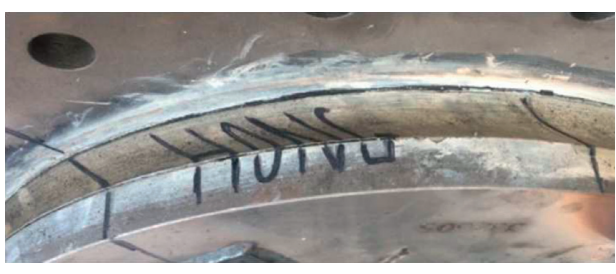

(b)

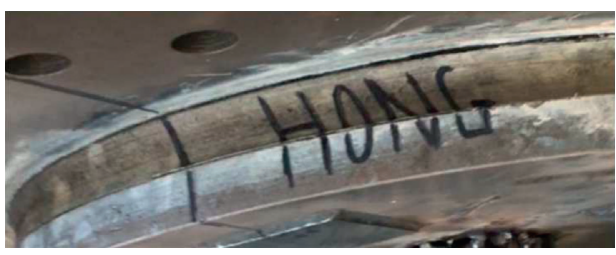

(d)

FiguRe 10: Loading process for Case 5. (a) Under $20 \mathrm{~mm}$ displacement. (b) Under $30 \mathrm{~mm}$ displacement. (c) State of the rubber after testing. (d) Gap between the rubber and the steel plate.

line goes down, and the amplitude of the reduction becomes smaller until a reverse-loading yield is reached. The shape of hysteresis loop is not affected by the number of loading cycles. For a displacement loading amplitude of $15 \mathrm{~mm}$, the hysteresis curves in the above cases exhibit the same postyield strengthening (increasing slope). As the loading frequency increases, the strengthening occurs at a slightly earlier time. This is due to the use of high-damping rubber, whose torsional contraction under large displacements causes its stiffness to suddenly increase, and the strengthening is related to the loading frequency. From the results of the fatigue test, it can be seen that the shape of the hysteresis curve does not change upon increasing the number of loading cycles. Under each loading cycle, the hysteresis loops basically overlap, and the damper does not show evident fatigue.

The hysteresis curve of the test specimen indicates an excellent energy consumption performance. For a small deformation state, the damper can form a full hysteresis loop to dissipate the energy. The hysteresis area under a large displacement is bigger and encloses the hysteresis loop corresponding to a small displacement. The hysteresis area obtained in the experiment is large, indicating that its energy consumption capacity is strong. Additionally, the shape of the hysteresis loop is not influenced by the number of cycles, and the performance is stable. The hysteresis curve is not completely symmetrical in the up and down regions but rather exhibits a bottom part that is larger than the top one. This is caused by the frictional resistance induced by the limit plate against the straight teeth, when the straight teeth are pressed down. Therefore, the peak force that is obtained during the upward pulling process represents a more suitable reference value. In short, the proposed DATD uses commonly available lead and rubber and combines the two materials to achieve a stronger energy dissipation mechanism, resulting in an excellent energy dissipation performance.

\section{Numerical Simulations of the DATD}

5.1. Finite Element Model of the DATD. Based on the size of the test component, the finite element model (FEM) was established using the software ABAQUS. The constructional rationality and the energy consumption performance of the DATD were evaluated through numerical analyses, which were then compared with the experiments. 


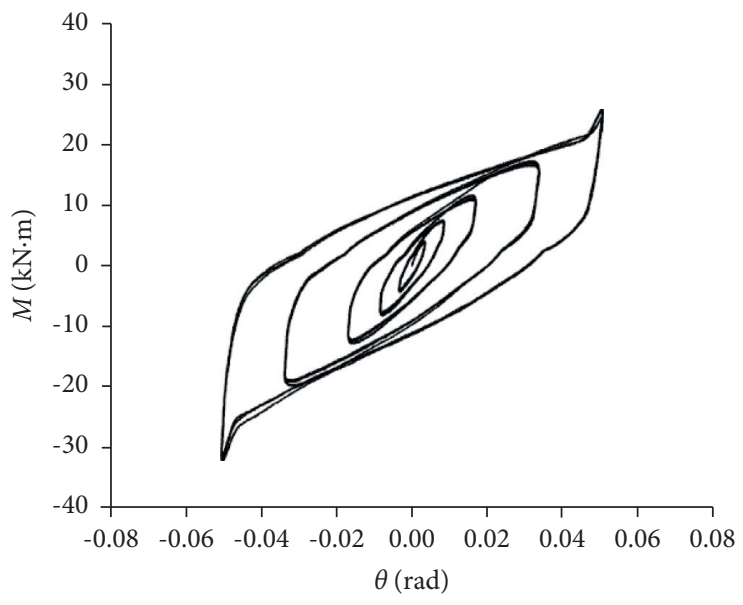

(a)

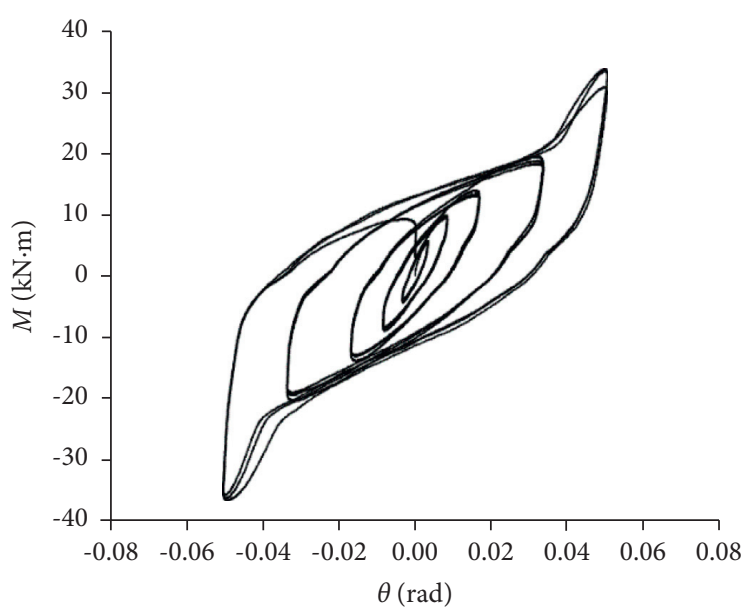

(c)

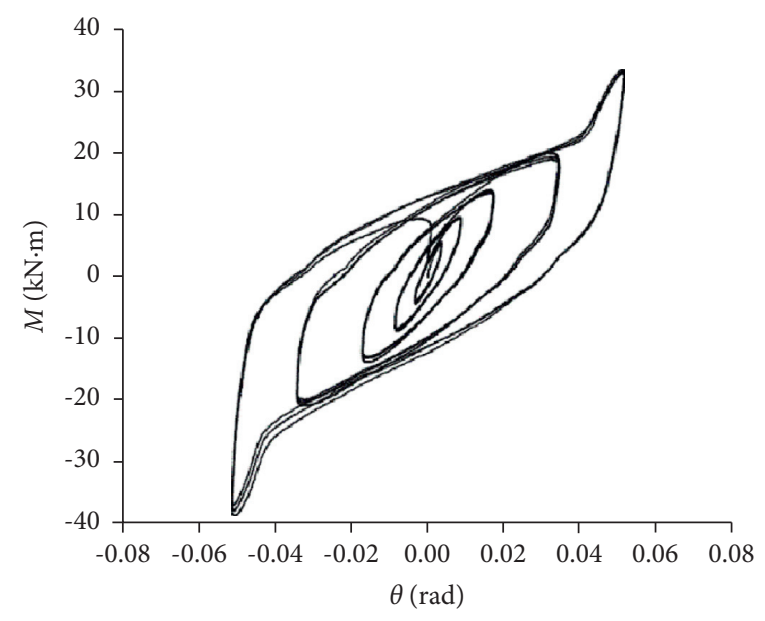

(b)

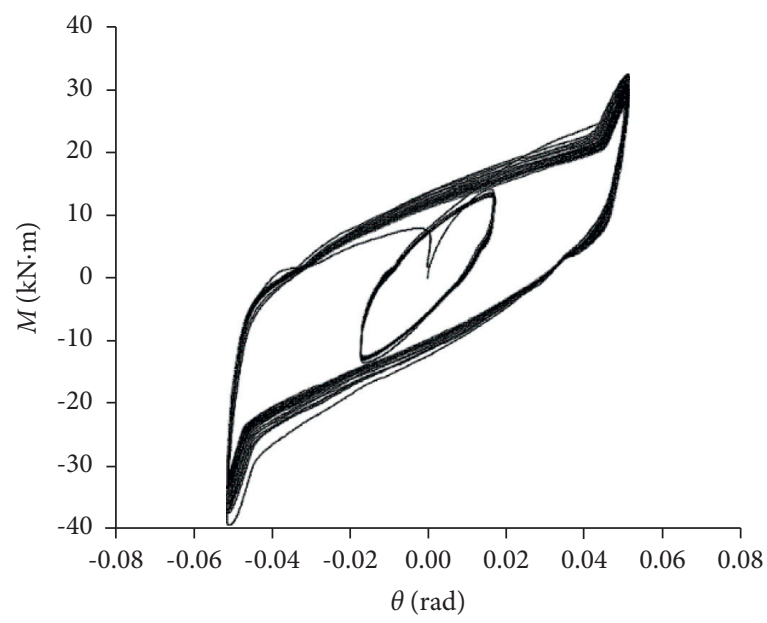

(d)

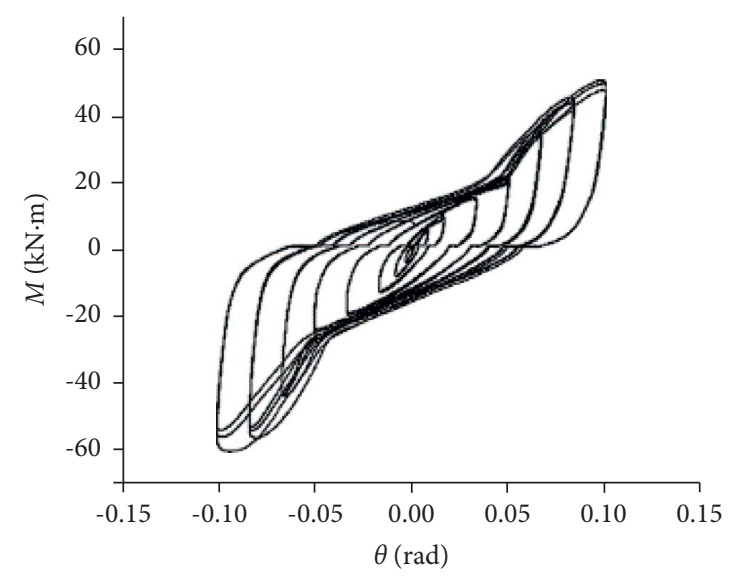

(e)

Figure 11: Hysteresis loops of the specimen under cases 1-5. (a) Case 1. (b) Case 2. (c) Case 3. (d) Case 4. (e) Case 5.

5.1.1. Simplifications Used in the FEM. The following three simplifications were adopted. Considering the computational efficiency and the convenience of meshing, the arc transmission steel arm was omitted from the model, so that the energy consumption mechanism could be studied more clearly.

Considering that the damper is geometrically symmetrical, the gear cylinders at both ends of the damper were set 
to be fixed in the model, and only the corresponding angular displacement was applied to the middle round steel plate, which is beneficial for load applications as well as for comparison with the experiments.

Since the three round steel plates do not participate in the deformation or in the energy consumption, they were here treated as rigid bodies, without considering either the force acting on them or the consequent deformation. Despite these simplifications, the model could meet the accuracy requirements, while also reducing the calculation time.

\subsubsection{Implementation of the Model for Each Component.} Firstly, a solid model for each component of the DATD was created. All the steel plates were assumed to be rigid bodies. The rubber layer was assumed to be a superelastic body, which was divided into five layers with a reference plane. The relationship between the rubber layer and the round steel plate was set as a binding constraint. The lead core was divided into five parts, which are in contact with each segment of the different materials (see Figure 12). A reference point RP1 on the central axis of the damper was selected (as shown in Figure 13) and bound to the middle round steel plate. The rotation of the middle round steel plate was achieved by applying a rotation around point RP1.

5.1.3. Material Properties. Q345 steel is an elastoplastic material, with elastic modulus $E_{\mathrm{s}}=2.06 \times 105 \mathrm{MPa}$ and Poisson's ratio $v=0.3$. The lead core can be considered as an ideal elastoplastic material. The tangent modulus of the lead core is zero, its yield stress is $10.5 \mathrm{MPa}$, its elastic modulus is $16.5 \mathrm{GPa}$, and its Poisson's ratio is 0.42 . Assuming that the rubber is isotropic and almost incompressible [24], its Poisson's ratio is close to 0.5 . The five-constant Mooney-Rivlin model $[25,26]$ was used to determine the parameters of the rubber and the five mechanical property constants, namely, $C_{10}=2.0601 e-1$, $C_{01}=1.8577 e-3, \quad C_{20}=4.1001 e-3, \quad C_{30}=2.8070 e-5, \quad$ and $C_{11}=1.0092 e-3$. The relationship between the elastic modulus and the material constants of the rubber is $E=6\left(C_{01}+C_{10}\right)$. Thus, $E=1.24 \mathrm{MPa}, G=E / 3=0.41 \mathrm{MPa}$, and $v=0.4997$.

5.1.4. Unit Selection. The DATD is composed of three materials: steel, lead core, and rubber. The C3D8R unit was used for the simulation of the steel plate and the lead core. This unit was chosen as it can provide more accurate calculation results for the displacement. The C3D8H unit was used to simulate the rubber.

5.1.5. Contact Definition. Since the lead core is in contact with different materials, it was divided into five parts. The surface-to-surface tie contact was adopted between the lead core and the round steel plate. Additionally, the contact surface of the round steel plate with a large rigidity was considered to be the master surface, whereas the contact surface of the lead core was taken as the slave surface. For the contact surface between the lead core and the rubber, the

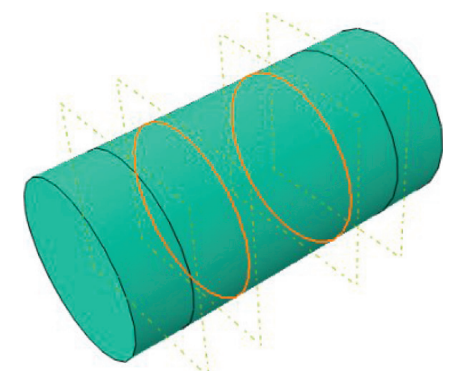

FIGURE 12: FEM of the lead core.

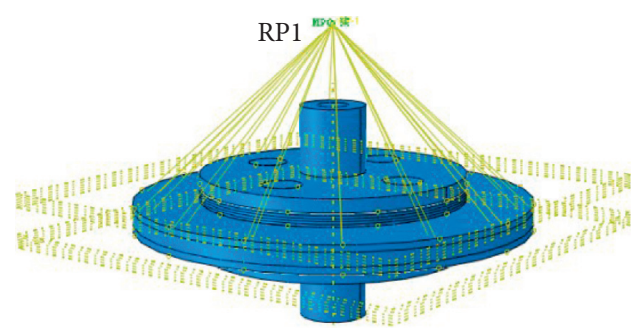

FIGURE 13: FEM and reference point (RP1) of the DATD.

"hard contact" mode was adopted in the normal direction, whereas the "Coulomb friction" mode was adopted in the tangential direction, with the friction coefficient being 0.5. The surface-to-surface slip formula with a small slip was used in the definition of the surface-to-surface contact. The upper and lower sides of the two gear cylinders were fully fixed, in order to define the boundary conditions. A reference point RP1 was created on the central axis. The rigid body binding contact was used to bring together the middle round steel plate and RP1 as a rigid body model. The loading could be applied to the reference point.

5.1.6. Meshing. Since the DATD is symmetrical, a sweep grid meshing method was used here [27]. For the upper and lower round steel plates, the global seed size was set to 15 , the approximate unit size of the local seed was 15 , and the maximum deviation factor was 0.1 . For the middle round steel plate, the above three values were set to 12,12 , and 0.1 , respectively. For the rubber layer, the corresponding values were 5,10 , and 0.1 . For the lead core, the corresponding values were 5, 5, and 0.4. Figure 14 shows the damper after meshing.

5.1.7. Constraints and Loading of the System. The DATD was fixed at both ends, and the reference point RP1 was set on the central axis to bind the middle round steel plate. The angular displacement was applied to the reference point, and 20 analysis steps were set, as shown in Figure 15.

5.2. Simulation Results and Comparison with Experiments and Theory. Figure 16 shows the comparison of the hysteresis curves of the DATD obtained from the FEM with the performance test and the theoretical analysis under Case 1. From Figure 16, it can be seen that the stiffness before 


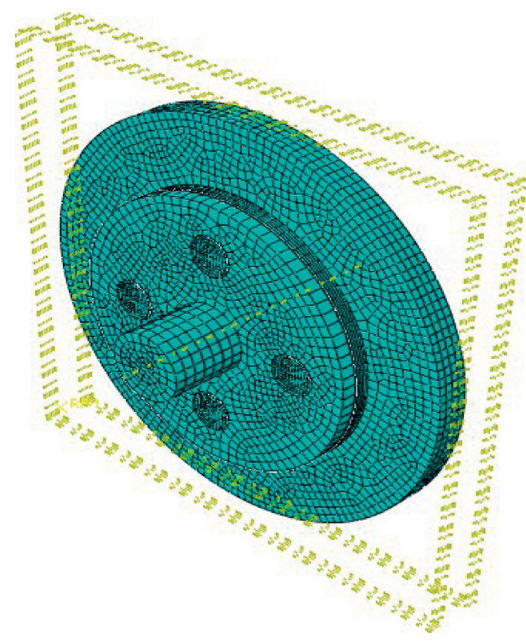

Figure 14: Meshing of the damper.

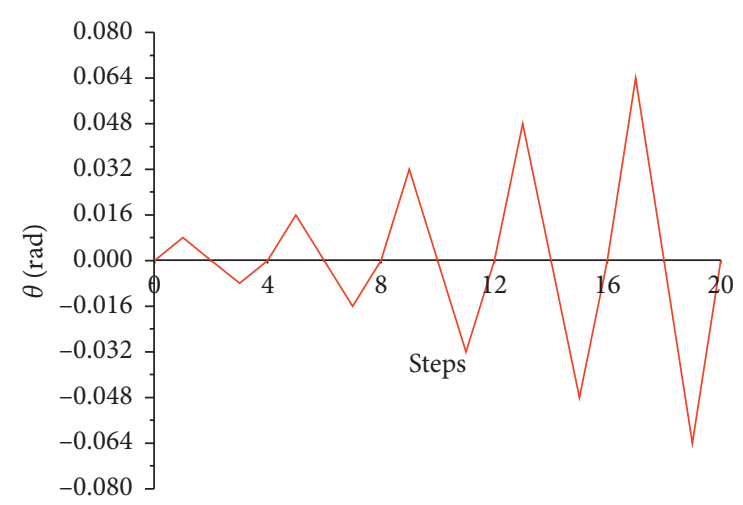

FIGURE 15: Loading curve.

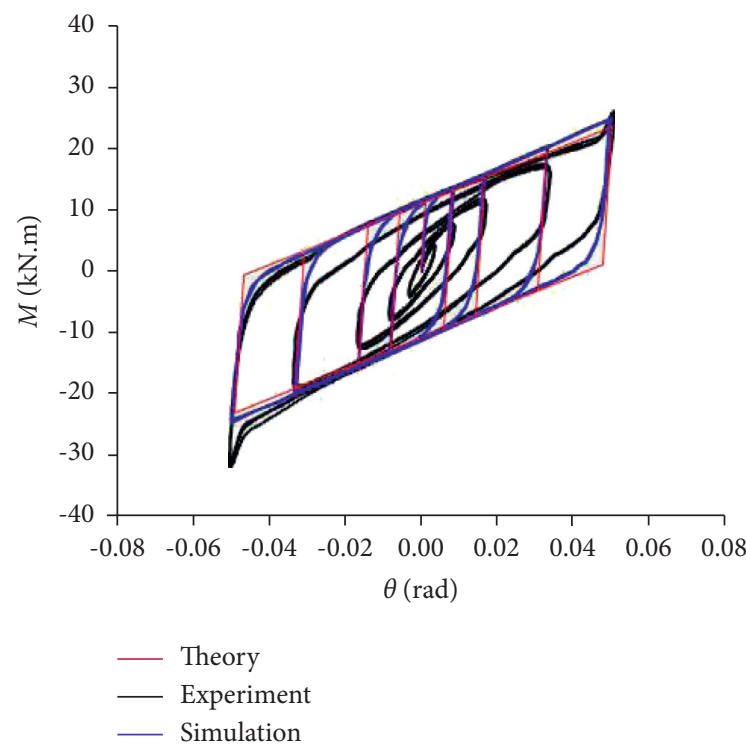

FIGURE 16: Comparison of the hysteresis curves between simulation, experiment, and theory. yielding is large; after yielding, the curve is basically a straight line, and the bending moment is linearly proportional to the angle of rotation. Next, the curve unloads along the initial stiffness then loads in reverse to yield. The shape of the hysteresis loop is not influenced by the number of cycles. The hysteresis loop is full and symmetrical, and the energy consumption is stable. The entire curve presents a parallelogram shape. The characteristics of the energy dissipation of the rubber in the shear hysteresis deformation are evident. This indicates that the damper is able to fully exploit the two energy-consuming materials together, achieving a stable performance. Furthermore, it can be seen that the hysteresis curves of the DATD obtained from the simulations and from the theoretical analysis are in good agreement in the elastic and elastoplastic sections of the load. However, the theoretical hysteresis curve is sharper when transitioning from the elastic section to the plastic one, compared with the simulated hysteresis curve. With respect to the simulated and theoretical results, the bearing capacity obtained experimentally under a small displacement is obviously much smaller, and the hysteresis loop area is also different. As the displacement increases, the disparity gradually decreases, and the experimental hysteresis curve shows increasingly better agreement with the theoretical and simulated curves.

Generally speaking, the hysteresis curve obtained via the numerical analysis coincides with the hysteresis curve obtained theoretically and experimentally. This confirms the validity of the numerical simulation method that can be thus used for subsequent analyses.

\section{Conclusions}

In this work, a novel DATD was proposed. The composition of the damper was firstly introduced, and the theoretical mechanical models of the damper were then derived. Cyclic loading tests and numerical analyses were also performed. Finally, the results of the theoretical, experimental, and numerical analysis were compared. The following conclusions could be drawn:

(1) The proposed DATD has a full hysteresis curve and a strong energy dissipation capacity. The shape and size of the hysteresis loop are not affected by the number of loading cycles. Within the limit of the elastoplastic displacement angle between the stories of the structure, the mechanical model of the DATD can be represented by a bilinear restoring mechanical model.

(2) The experimental results show that the DATD has a good energy consumption effect under a small displacement. Under large displacements, a strengthening phenomenon occurs due to the sudden increase of the bearing capacity. This is due to the torsional contraction of the high-damping rubber used in the damper, which causes an increase in the stiffness under a large displacement. The theoretical analyses and simulations have not considered this strengthening effect. 
(3) The comparison of the results between the experiments, simulations, and theory shows that, under small displacements, the bearing capacity measured experimentally is significantly smaller than the one obtained from the simulation and the theory, and the hysteresis area is also quite different. As the loading amplitude increases, the experimental results become closer to those of the simulation and the theory; the hysteresis curves obtained from the three methods become increasingly more similar, and the diversity of the hysteresis area is reduced. This is due to the existence of gaps between the gear contacts or inside the damper in the test and to the fact that the damper cannot be fully loaded under small displacements.

(4) Another difference evinced between the hysteresis curve from the experiment, simulation, and theoretical analysis involves the nature of the elastoplastic transition. The hysteresis curve obtained via the bilinear model used in the theoretical analysis does not show a smooth elastoplastic transition section. On the other hand, both the experiment and the simulation results are characterized by a smooth elastoplastic transition section.

(5) The hysteresis curves obtained via the theoretical analysis and the simulation are symmetrical, whereas the hysteresis curve obtained experimentally is asymmetrical, with the upper curve being smaller than the lower one. This is due to the presence of slippages and obvious gaps between the straight teeth and the gear of the middle round steel plate in the test. Furthermore, the limit plate and the straight teeth are not parallel, giving rise to a considerable friction upon pressing down, which is not considered either in the theory or in the simulation.

(6) Under a larger displacement loading amplitude, the hysteresis curve obtained via the numerical analysis is in good agreement with that derived from the experiment. This indicates that the numerical simulation is accurate and suitable to model the damper. These results confirm that the proposed DATD is feasible.

\section{Data Availability}

The data used to support the findings of this study are included within the article. Requests for the original test data, 12 months after publication of this article, will be considered by all authors and should be made to the corresponding author.

\section{Conflicts of Interest}

The authors declare that they have no conflicts of interest.

\section{Acknowledgments}

The authors acknowledge the support from the National Natural Science Foundation of China (Grant no. 51578160), the Science and Technology Planning Project of Fujian (Grant no. 2018Y0057), and the Tianjin University-Fuzhou University Independent Innovation Fund Cooperation Project (Grant no. TF2021-9).

\section{References}

[1] Y. J. Xin and S. L. Cheng, "Numerical simulation of I-section combined steel lead damper," in Proceedings of the international conference on mechanic automation \& control engineering, IEEE, Wuhan, China, June 2010.

[2] H.-N. Li, M.-M. Liu, and X. Fu, "An innovative re-centering SMA-lead damper and its application to steel frame structures," Smart Materials and Structures, vol. 27, no. 7, Article ID 075029, 2018.

[3] X. Zhang, X. Zhang, Y. Zhao, J. Zhao, and Z. Xu, "Experimental and numerical studies on a composite MR damper considering magnetic saturation effect," Engineering Structures, vol. 132, pp. 576-585, 2017.

[4] Y. Zhong, J. Tu, Y. Yu, J. Xu, and D. Tan, “Temperature compensation in viscoelastic damper using magnetorheological effect," Journal of Sound and Vibration, vol. 398, pp. 39-51, 2017.

[5] M. Sanati, S. E. Khadem, S. Mirzabagheri, H. Sanati, and M. Y. Khosravieh, "Performance evaluation of a novel rotational damper for structural reinforcement steel frames subjected to lateral excitations," Earthquake Engineering and Engineering Vibration, vol. 13, no. 1, pp. 75-84, 2014.

[6] B. Silwal, R. J. Michael, and O. E. Ozbulut, "A superelastic viscous damper for enhanced seismic performance of steel moment frames," Engineering Structures, vol. 105, pp. 152-164, 2015.

[7] B. Silwal, O. E. Ozbulut, and R. J. Michael, "Seismic collapse evaluation of steel moment resisting frames with superelastic viscous damper," Journal of Constructional Steel Research, vol. 126, pp. 26-36, 2016.

[8] C. Fang, Y. Ping, Y. Chen, M. C. H. Yam, J. Chen, and W. Wang, "Seismic performance of self-centering steel frames with SMA-viscoelastic hybrid braces," Journal of Earthquake Engineering, vol. 3, pp. 1-28, 2020.

[9] A. Banisheikholeslami, F. Behnamfar, and M. Ghandil, "A beam-to-column connection with visco-elastic and hysteretic dampers for seismic damage control," Journal of Constructional Steel Research, vol. 117, pp. 185-195, 2016.

[10] M. Yamamoto and T. Sone, "Damping systems that are effective over a wide range of displacement amplitudes using metallic yielding component and viscoelastic damper in series," Earthquake Engineering \& Structural Dynamics, vol. 43, no. 14, pp. 2097-2114, 2015.

[11] R. Vargas and M. Bruneau, "Effect of supplemental viscous damping on the seismic response of structural systems with metallic dampers," Journal of Structural Engineering, vol. 133, no. 10, pp. 1434-1444, 2007.

[12] R. Soltanabadi, A. Mamazizi, and F. Behnamfar, "Evaluating the performance of chevron braced frame with RSCD viscoplastic damper," Engineering Structures, vol. 206, Article ID 110190, 2020.

[13] H. Kim, Y. H. Lee, H. Park, D. J. Him, J. W. Park, and J. Y. Park, "Performance of a lead rubber damper under cyclic shear loading and its applicability to a full-scale structure," Journal Vibroengineering, vol. 17, no. 5, pp. 2471-2479, 2015.

[14] K. Zeynali, H. Saeed Monir, N. M. Mirzai, and J. W. Hu, "Experimental and numerical investigation of lead-rubber dampers in chevron concentrically braced frames," Archives of 
Civil and Mechanical Engineering, vol. 18, no. 1, pp. 162-178, 2018.

[15] X. Yan, Z. Chen, A. Qi, X. Wang, and S. Shi, "Experimental and theoretical study of a lead extrusion and friction composite damper," Engineering Structures, vol. 177, pp. 306-317, 2018.

[16] J. Lee, H. Kang, and J. Kim, "Seismic performance of steel plate slit-friction hybrid dampers," Journal of Constructional Steel Research, vol. 136, no. 9, pp. 128-139, 2017.

[17] C.-H. Lee, J. Kim, D.-H. Kim, J. Ryu, and Y. K. Ju, "Numerical and experimental analysis of combined behavior of shear-type friction damper and non-uniform strip damper for multi-level seismic protection," Engineering Structures, vol. 114, pp. 75-92, 2016.

[18] J.-E. Roh, M.-W. Hur, H.-H. Choi, and S.-H. Lee, "Development of a multiaction hybrid damper for passive energy dissipation," Shock and Vibration, vol. 2018, Article ID 5630746, 16 pages, 2018.

[19] Y. E. Ibrahim, J. Marshall, and F. A. Charney, "A visco-plastic device for seismic protection of structures," Steel Constr, vol. 63, no. 11, pp. 1515-1528, 2008.

[20] J. L. Li and J. P. Ou, "Damping force models and designs of lead shear dampers," Engineering Mechanics, vol. 23, no. 4, pp. 67-73, 2006.

[21] C. X. Wu, X. Xu, Y. Zhou, and C. Zhang, "Restoring force model and design method of sector lead viscoelastic damper," Journal of Vibration and Shock, vol. 34, no. 12, pp. 18-22, 2015.

[22] P. Yin, L. Li, and Z. P. Liang, "Wind-induced vibration control for electrical transmission towers by using lead viscoelastic dampers," Journal of Vibration and Shock, vol. 26, no. 8, pp. 1-4, 2007.

[23] K. Yoshida and T. Fujio, "Semi-active base isolation for a building structure," International Journal of Computer Applications in Technology, vol. 13, no. 1/2, p. 52, 2000.

[24] M. Zheng, W. Wang, and Z. Chen, "Determination for mechanical constants of rubber Mooney-Rivlin model," China Rubber Industry, vol. 8, pp. 462-465, 2003.

[25] L. A. Gracia, E. Liarte, J. L. Pelegay, and B. Calvo, "Finite element simulation of the hysteretic behaviour of an industrial rubber. Application to design of rubber components," Finite Elements in Analysis and Design, vol. 46, no. 4, pp. 357-368, 2010.

[26] M. Takayama, H. Tada, and R. Tanaka, "Finite-element analysis of laminated rubber bearing used in base-isolation system," Rubber Chemistry and Technology, vol. 65, no. 1, pp. 46-62, 1992.

[27] E. Giner, N. Sukumar, J. E. Tarancón, and F. J. Fuenmayor, "An Abaqus implementation of the extended finite element method," Engineering Fracture Mechanics, vol. 76, no. 3, pp. $347-368,2009$. 